NBER WORKING PAPER SERIES

\title{
PRECAUTIONARY SAVINGS, RETIREMENT PLANNING AND MISPERCEPTIONS OF FINANCIAL LITERACY
}

\author{
Anders Anderson \\ Forest Baker \\ David T. Robinson \\ Working Paper 21356 \\ http://www.nber.org/papers/w21356 \\ NATIONAL BUREAU OF ECONOMIC RESEARCH \\ 1050 Massachusetts Avenue \\ Cambridge, MA 02138 \\ July 2015
}

Previously circulated as "Optimism, Financial Literacy and Participation." We are grateful to Johan Almenberg, Enrica Bolognesi, Harrison Hong, Olivia Mitchell, Terry Odean, Richard Sias, Paul Smeets, Zheng Sun, and seminar participants at Stockholm School of Economics, Stockholm Business School, BI Oslo, Gothenburg, Georgia Tech, Lund, Maastricht, Tilburg, Duke University, the 2014 UNSW Australasian Banking and Finance conference, the 2015 WFA meetings, the 2015 Behavioral FinanceWorking Group Conference at the University of London, for useful comments and we thank Susan Sumida for excellent research assistance. This research does not express the views of LinkedIn and has been funded by Vinnova and the Nasdaq OMX Foundation. The views expressed herein are those of the authors and do not necessarily reflect the views of the National Bureau of Economic Research.

NBER working papers are circulated for discussion and comment purposes. They have not been peer-reviewed or been subject to the review by the NBER Board of Directors that accompanies official NBER publications.

(C) 2015 by Anders Anderson, Forest Baker, and David T. Robinson. All rights reserved. Short sections of text, not to exceed two paragraphs, may be quoted without explicit permission provided that full credit, including $(\odot$ notice, is given to the source. 
Precautionary Savings, Retirement Planning and Misperceptions of Financial Literacy Anders Anderson, Forest Baker, and David T. Robinson

NBER Working Paper No. 21356

July 2015, Revised July 2016

JEL No. G02

\begin{abstract}
$\underline{\text { ABSTRACT }}$
We measure financial literacy among LinkedIn members, complementing standard questions with additional questions that allow us to gauge self-perceptions of financial literacy. Average financial literacy is surprisingly low given the demographics of our sample: fewer than two-thirds of CFOs, CEOs, and COOs complete the test correctly. Financial literacy, precautionary savings and retirement planning are positively correlated, but this is mostly driven by perceived, not actual, literacy: controlling for self-perceptions, actual literacy has low predictive power. Perceptions drive decision-making among low-literacy respondents and are associated with mistaken beliefs about financial products and less willingness to accept financial advice.
\end{abstract}

Anders Anderson

Stockholm School of Economics

Drottninggatan 98

Stockholm, Sweden

Anders.Anderson@hhs.se

Forest Baker

LinkedIn Corporation

San Francisco, CA

fbaker@linkedin.com
David T. Robinson

Fuqua School of Business

Duke University

100 Fuqua Drive

Durham, NC 27708

and NBER

davidr@duke.edu 


\section{Introduction}

As retail financial markets grow increasingly opaque and the responsibility for financial planning shifts more towards individuals, greater and greater amounts of financial sophistication are required just to make ordinary household financial decisions. Yet financial literacy appears to be in short supply (Lusardi and Mitchell, 2005). Given that financial literacy has been shown to be positively correlated with a number of important household financial behaviors, such as retirement planning and precautionary savings, this places financial literacy at the center of a broad national discussion about consumer financial protection (Hastings, Madrian and Skimmyhorn, 2013) and household financial security (Lusardi, Schneider and Tufano, 2011).

At the same time, a large body of work in behavioral economics and psychology demonstrates that people hold biased self-perceptions. These biases are likely to be especially important in the domain of household finance, where simple heuristics are used in complex decision environments, and where meaningful feedback about the efficacy of these heuristics is noisy and infrequent. In such environments, individuals can persistently hold (and act on) mistaken beliefs about their own financial acumen.

In this paper we connect behavioral finance to household finance by asking how misperceptions of financial literacy relate to household precautionary savings and retirement planning decisions. While it is well established that observed financial literacy is correlated with savings and retirement planning, our central message is this: how financially literate people think they are is a better predictor of their precautionary savings and retirement planning decisions than how financially literate people actually are.

We also show that people who are more miscalibrated about their own financial literacy are more likely to be wrong about financial matters that fall outside the standard financial literacy test. Thus, their misperceptions may lead them to make suboptimal financial decisions. In addition, lower scoring individuals appear to be unaware that they lack financial literacy. At the same time, miscalibrated individuals are also less open to accepting financial planning advice. This sheds light on why their behaviors may be disproportionately difficult to change with education- or advice-oriented interventions.

We connect behavioral biases to household decision-making through a financial literacy 
survey administered to a large sample of LinkedIn subscribers as part of a larger, monthly omnibus survey conducted by the LinkedIn corporation. We administer a standard financial literacy test, augmenting the "Big 3" financial literacy questionnaire pioneered by Lusardi and Mitchell $(2005,2009)$ with two additional questions that have been extensively used in the previous literature, including in the 2009 and 2012 U.S. National Financial Capability Study (NFCS). Following Hastings et al (2013), we collectively label these questions the "Big 5".

Next we measure how respondents think they did on the test. We adapt the methodology of Moore and Healy (2008) by asking respondents to report how likely it is that they got all five questions, four questions, three questions, etc., correct. By effectively eliciting a probability distribution over possible test outcomes, we can distinguish two different types of misperceptions about ability. By comparing the actual score to the subjective expected score, we can recover what Moore and Healy (2008) call overestimation, which is when a person thinks they are better than they actually are. Second, by observing how subjective probability is spread over the possible outcomes, we can measure the degree of precision that they attach to those beliefs. This methodology allows us to measure how certain people are of their expected performance, regardless of whether they think they did well or poorly.

We can group our findings into four main sets of results. The first concerns the observed degree of financial literacy in our sample. Although average financial literacy in our sample is a good deal higher than what has been found in previous work - a fact which owes at least in part to the nature of our sample - we find clear evidence of widespread financial illiteracy. More than one-third of CFOs, CEOs, and COOs in our sample do not answer all five questions correctly. Only about twenty-five percent of students gets all five correct, and fewer than half of Director, Managing Director or Department Head level members receive perfect scores. In addition, most individuals think past performance is more important than fees when choosing mutual funds. Given that our sample consists of tech-savvy, white-collar professionals, a large fraction of whom make more than twice the U.S. national average income, it is reasonable to ask whether the financial literacy rates we measure should not be a great deal higher. 
The second set of findings concerns the connection between perceived literacy and actual financial literacy. In general, respondents who lack financial literacy think they are more literate than they actually are. As in many other studies, we find that women score lower on this type of test compared to men, but unlike men, they are less likely to overestimate their financial literacy.

Kruger and Dunning (1999) argue that possession of a skill is in fact necessary to make correct judgements of competence in that same domain, giving rise to systematic bias in self-assessments. Such individuals not only reach mistaken conclusions, but their incompetence also robs them of the ability to realize their mistakes. This meta-cognition is an important element of our findings as well. A large number of perfect-scorers attach $100 \%$ probability to getting all five answers correct: they know that they know. However, among less than perfect scorers, lower scorers are at least as likely to be certain of their outcome as higher scorers, and those who do are much more likely to be wrong. In short, low scorers do not know that they do not know.

Our second set of results relates real and perceived financial literacy to precautionary savings and retirement planning. In particular, we ask respondents whether they have set aside funds for emergencies, as well as whether they had attempted to compute how much they would need for retirement, whether they are sole decision-makers of their housholds, and whether they were in favor or opposed to receiving financial advice. These correspond to questions used extensively in existing work on financial literacy. ${ }^{5}$

The main result from this section is that beliefs are at least as important for predicting precautionary savings and retirement decisions as actual literacy. In fact, when we control for beliefs, the well documented tendency for women to participate less in financial market decisions becomes much weaker. ${ }^{6}$ In general, respondents' mistaken beliefs about their financial literacy drive their behavior to a at least the same degree as their actual literacy.

Our final set of results asks whether mistaken beliefs are good or bad for the people who harbor them. We introduce a financial knowledge question about mutual funds: whether it

\footnotetext{
${ }^{5}$ See, for example, Ameriks et al. (2003), Hilgert et al. (2003), Lusardi and Mitchell (2011b), and Lusardi and Mitchell (2011a).

${ }^{6}$ See Lusardi and Mitchell (2008) for evidence on women and financial planning.
} 
is better to focus on fees or past performance. The exact language of this question closely mirrors financial advice promulgated by the SEC on their website. ${ }^{7}$ Holding constant actual financial literacy, people who overestimate their score are less likely to respond that they do not know the answer, but more likely to get the answer wrong. These respondents are also less likely to be receptive to financial advice.

Establishing the distinction between financial competence and financial confidence suggests a number of possible mechanisms connecting financial literacy and financial planning decisions that are new to the literature. One is that self-perceptions directly lower the perceived costs of engaging in financial planning decisions in the same way that actual knowledge does - an individual thinks it is easy to plan for retirement, therefore they do, whereas someone with a greater appreciation of the pitfalls of retirement planning is reluctant to begin the task in the first place. Indeed, self-confidence has been shown to be an important driver of behavior in a variety of different market settings (see Camerer and Lovallo (1999), Hong et al. (2004), or Barber and Odean (2000).) A second possible mechanism is that individuals attempt to plan for retirement or set aside savings, and these actions either rightly or wrongly imbues them with a sense of financial literacy. In other words, financial planning causes actual financial literacy by stimulating a sense of perceived literacy.

Our data set is not the first that allows for self-perceptions and actual financial literacy to be compared. The NFCS includes questions about an individual's broad sense of financial

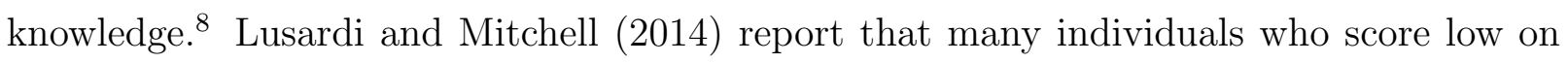
financial literacy tests report that they think they are knowledgeable. Allgood and Walstad (2012), Parker et al. (2012) and Van Rooij et al. (2011) also relate actual literacy and perceived knowledge to one another. One key difference between our paper and these papers is that we explicitly anchor the respondents' self-assessment on their financial literacy test score, rather than a broad pre-conceived notion of their financial knowledge. ${ }^{9}$ Our results

\footnotetext{
${ }^{7}$ See http://investor.gov/investing-basics/investment-products/mutual-funds\#Fees.

${ }^{8}$ In the online appendix we develop similar results to the ones in this paper using the 2012 State-by-State NFCS.

${ }^{9}$ Our work is also distinct from the literature that considers role of broad-based measures of optimism or other pro-social behaviors in shaping retirement planning and savings decisions. See Puri and Robinson (2007) or Hong et al. (2004) and cites therein for examples.
} 
are also helpful in explaining the dispersion of beliefs compared to scores, as we tie them to established results from psychology.

The remainder of the paper proceeds as follows. In Section 2 we detail the data collection issues surrounding our survey instrument and the sample that responded to our survey, as well as present details on the techniques we use to elicit beliefs. Section 3 presents our results on actual and perceived financial literacy, and Section 4 connects them to our measures of financial behavior. In Section 5 we discuss whether mistaken beliefs are good or bad for the people who hold them, while section 6 concludes.

\section{Measuring Financial Literacy, Beliefs, and Financial Behaviors}

Most research in financial literacy has focused on a small set of questions that are meant to capture peoples' overall financial knowledge, and cover topics such as compounding, inflation, interest, diversification, and bond pricing. ${ }^{10}$ These questions form the baseline starting point for our analysis.

-Table 1 about here-

Table 1 display the five (first three) questions which we refer to as the "Big 5" ("Big 3" ), following the labelling of Hastings et al. (2013). A large body of work links the score of these questions to different financial behaviors, and find that more financially literate people are more likely to save, plan for retirement, pick up credit information, and have better diversified portfolios. We opt to use the same set of questions in order to be able to compare our results to the 2012 State-by-State NFCS, which is designed to be representative of the U.S. population.

\subsection{The LinkedIn Sample}

To measure financial literacy among LinkedIn subscribers, we augmented the January and July, 2014, versions of a monthly omnibus survey that LinkedIn sends to its membership base. ${ }^{11}$ We added the Big 5 financial literacy questions to their standard omnibus survey

\footnotetext{
${ }^{10}$ Lusardi and Mitchell (2014) and Hastings et al. (2013) provide overviews.

${ }^{11}$ LinkedIn is an online professional networking website founded in 2003 in which members can post resume information and work profiles. See www.ourstory.linkedin.com for details.
} 
and included additional questions that measured financial knowledge, beliefs and financial behaviors.

Subjects were invited to take the survey with an e-mail that contained a link to a webpage with the omnibus survey questions. We surveyed twice: in January and July, 2014. There were 223,768 and 247,543 members invited in the two waves, respectively. This is a random sample of U.S. LinkedIn users who had logged into their account at least once in the last year and had not been asked to take a survey in the last 30 days. We deleted incomplete responses, including those who reported "Don't know" or "Prefer not to answer" to the beliefs question, as well as those finishing the survey under two minutes. Our full sample consists of 5,814 responses, of which 2,393 $(3,421)$ appeared in the first (second) wave. Respondents spent 8:41 (12:18) minutes:seconds to complete the survey in the first (second) wave, on average. The response rates we received are typical for this type of survey.

Table 2 presents the sample statistics on demographics for our LinkedIn sample, along with statistics for the U.S. population taken from the 2012 U.S. Census Bureau (denoted "U.S. Pop."), as well as the 2012 NFCS State-by-state study (intended to be a representative sample). LinkedIn members are clearly not representative of the U.S. population. Only one third are women. The median age in our sample is 47 compared to 37 in the overall population, but the partition across age groups in Table 2 reveals that this is mainly due to the fact that most LinkedIn members are found in the working-ages between 35 to 64 , and many fewer among those likely to be retired over 65 or still studying under 25. A striking difference to the population in general is the higher income and education in our sample. Two thirds of the LinkedIn members have a university degree, where one third hold a Bachelor's, and one third at least a Master's degree. In the overall population, $19 \%$ hold a Bachelor's, and only 12\% have earned a Master's degree or more. Similarly, almost a quarter of LinkedIn members have yearly household income exceeding $\$ 150 \mathrm{~K}$, whereas only $9 \%$ in the U.S. population. Through their LinkedIn profiles, we also have statistics on respondents profession, and find that $12 \%$ report that they work in the financial industry, and we identify $17 \%$ to be entrepreneurs (small business owners or self-employed).

- Table 2 about here- 
Our sample is tilted towards higher income, well educated males. We believe that the demographics of our survey respondents closely match the underlying demographics of the LinkedIn population of users. LinkedIn does not collect data on age, gender or income from their members, but confirm that our results are broadly consistent with what is found in other analysis of their customer base. In untabulated results, we find that women have higher representation in the higher education categories, but do not exceed $40 \%$. The demographics between the two waves are very similar, so we combine them in the following analysis, treating them as one sample.

In what follows, we focus our analysis on respondents aged 25-64 to zero in on those most likely to be concerned with financial planning decisions. For our purposes, it is less meaningful to use responses of, for example, retirement decisions from very young people, or those who are already in retirement. We therefore opt to drop 918 observations from the full sample, and use 4,896 responses in the remainder of the paper. All of our results remain, but are statistically stronger, when the young and old are included.

In summary, the prototypical LinkedIn subscriber is a tech-savvy, white-collar working professional. Hence, compared to the average U.S. citizen, this demographic group may be more representative of the underlying financial knowledge on a consumption- or participation-weighted basis in the economy.

\subsection{Measuring Beliefs and Behaviors}

The psychology literature offers three distinct definitions of overconfidence. The first is

the overestimation of one's actual ability, performance, or chance of success. The second variety of overconfidence is excessive certainty regarding accuracy of ones beliefs, or what we will henceforth call precision. The third variety, which we do not explore in this paper, is what is generally referred to as the better-than-average effect or overplacement, in which one think of oneself as doing better than others. Most research in behavioral finance does not explicitly measure or identify which particular form of overconfidence that drives the behavior under study. Rather, as noted by Shiller (1999), it is referred to as a general mechanism to explain a wide variety of financial behavior, including trading, risk-taking, forecasting, and stock market overreaction. 
There are at least two challenges associated with measuring self-confidence in our setting. The first challenge is to elicit beliefs with accuracy. A common way to elicit broadbased beliefs about financial literacy is to ask subjects to rank their overall competence of financial decision-making, as in is done in the NFCS. The problem with such a methodology is that it may capture other aspects of financial literacy not covered by the test, making this information complementary to the test score. Instead, our approach is intended to capture beliefs about overall performance on the test itself, which in turn facilitates measurement of the psychological constructs.

The second challenge is to distinguish overestimation from confidence. When asking respondents to report their confidence in getting a specific question right, overestimation and precision are one and the same thing. Being excessively sure you got the item right reflects both overestimation of your performance and excessive confidence in the precision of your knowledge. Therefore, such a methodology can not distinguish between the two, and it does not allow measuring the prevalence of underestimation.

In this paper, we circumvent these challenges by building on the work of Moore and Healy (2008), who propose a method to elicit two separate measures of overconfidence. After completing the financial literacy questions, respondents are asked to state the probability that they got a certain number of answers correct. ${ }^{12}$ Figure 1 displays a screenshot of the question used in our survey.

-Insert Figure 1 here-

The responses then give us a complete distribution of beliefs, which allows us to define three key concepts used in the paper:

- Perceived score. The mean of the belief distribution, or self-assessed expected score.

- Overestimation. The difference between a subject's expected score and actual score. Overestimation therefore measures the mismatch between the subject's expected score and the actual outcome. In particular, while we use the term overestimation to keep with the psychology literature, it is important to note that this measure can

\footnotetext{
${ }^{12}$ The survey software required respondents to supply a range of numbers that summed to $100 \%$.
} 
be positive or negative: indeed, some respondents think they are worse than they actually are.

- Precision. The sum of squared weights of the belief distribution. This is similar to a Herfindahl index, and is bounded from above by one, as perfect confidence implies putting all mass in one particular category.

Asking respondents to provide a probability distribution over the total number of questions has several advantages relative to alternative scoring schemes. As noted above, asking respondents to assess the probability of each individual question correct would not allow us to form distinct but connected measures of optimism and confidence. The two measures also allows for a more comprehensive analysis of scores and self-perceptions.

To this, we include a number of questions about important financial decision-making behaviors. In keeping with prior work, we include standard questions about precautionary savings and retirement planning borrowed from the NFCS, and in addition, a question about and household investment decision-making. In sum, these questions are:

- Savings: Have you set aside emergency or rainy day funds that would cover your expenses for three months, in case of sickness, job loss, economic downturn, or other emergencies? (Wave 1 and Wave 2)

- Retirement: Have you ever tried to figure out how much you need to save for your retirement? (Wave 1 and Wave 2)

- Decision-maker: Which of the following best describes your role in making financial investment decisions? (Wave 2 only)

For the decision-maker question, respondents were asked to choose between three responses: that they were the primary decision-maker, that they shared responsibility, or that someone else had responsibility. The exact language is discussed in Section 4. In the second wave of data collection, we also added a number of questions that allowed us to gain insight into the mechanisms behind the connections between beliefs, financial literacy, and decision-making. We describe these in greater detail in Section 5. 


\section{Financial Literacy: Perception and Reality}

\subsection{Comparing Actual and Perceived Financial Literacy}

Figure 2 reports Actual and Perceived financial literacy for the overall sample. The average perceived score is computed using the probability weights across scores. These are plotted against actual scores in the same figure. The dotted 45-degree line benchmarks perfect alignment of expectations.

\section{-Include Figure 2 here-}

The fact that the solid line is above the 45-degree line for the lower-ability part of the sample means that those with lower scores tend to overestimate the outcome of the test. This is a very general result that has been found in numerous studies and tested in a variety of domains, see for example Lichtenstein et al. (1982). People who face difficult questions tend to overestimate their ability to know the correct answer, while the reverse is true for easy tasks. Our results confirm these findings on a general level, since average miscalibration is much higher for those with lower scores, compared to those with the highest, implying that there is a systematic effect when sorting on outcomes of the test.

Specifically, the flatness of the solid line in Figure 2 presents a clear illustration of the Kruger-Dunning effect. Kruger and Dunning (1999) attributes this feature to the fact that skills that engender competence in a certain domain are the very same skills necessary to evaluate competence. Hence, those with low knowledge tend to overstate their score, which is also found in laboratory experiments by Moore and Healy (2008). Table 3 shows the means of the Average and Perceived score are very similar, 4.09 compared to 4.00. This could well be a consequence of the financial literacy test to be considered an easy task for most people in our sample. We still find that a slight majority of respondents, 54\%, overestimate their score.

In support of this interpretation, the bars in Figure 2 displays the effect of metacognition by measuring the fraction of respondents who report a Precision score equal to one: those who are certain of the outcome of the test. The bars are broken up on being either correct or wrong about this assessment (see also Panel A of Table 3). We find that $32 \%$ of all our respondents report that they are certain of their test score, of which $20 \%$ 
correctly put all probability mass at the actual outcome. The remaining $12 \%$ were wrong, meaning that they put all probability mass at some other outcome. This effect is systematic across levels of score. Of those with full score, $44 \%$ were absolutely confident of their actual score, of which $40 \%$ were correct. Of those who scored two or less, $27 \%$ were certain of it, but $19 \%$ actually wrong. For all groups, except those having full score, certainty is therefore generally associated with being wrong rather than correct, and this effect grows larger as scores become lower.

-Include Table 3 about here-

Panel B of of Table 3 display the correlations between the variables, and show that Precision is very highly correlated with being sure, $78 \%$, whereas the relation to Perceived score and Overestimation is much weaker, measured to be $31 \%$ and $20 \%$. Perceived score is positively correlated with being sure about the outcome, but since self-assessed scores are highly correlated with actual outcomes, the correlation masks the residual component of accuracy. Overestimation shows a much higher correlation with being sure and wrong $(23 \%)$, than being sure and correct (5\%). These preliminary results therefore suggest that overestimation captures an additional effect that goes beyond the channel of financial literacy: the responses from those thinking they know, but are actually wrong.

To get a better sense of the distribution of Perceived scores, we plot the joint distribution of Perceived and Actual scores in Figure 3. The graph is helpful when interpreting many of our key results with respect to explaining our measures of financial behavior. When we control for the effect of Actual score in the regressions and include our measure of beliefs, one can think of this as holding the vertical dimension constant in Figure 3, and investigating the separate effects of beliefs in the horizontal dimension.

\section{-Include Figure 3 about here-}

Figure 3 shows a clear pattern in which those who score very low or very high display more confidence in their assessment of beliefs. If assessments across scores were similar, we would expect a ridge going from the lower left corner of the graph to the upper right. This is clearly not the case. Precision is a measure of this effect. Column (4) of Panel 
A in Table 3 shows that Precision is 0.79 and 0.65 for those who scored 5 and 4 , falling to 0.58 for those scoring 2 or less. There is a slight tendency for those who score zero to report higher Precision, but there are few observations in this group. We therefore treat the group scoring 0 to 2 as one category. There are 1,847 respondents answering all five questions correctly, 2,022 scored four, 713 score three, leaving the remaining 314 responses in the lower three categories zero to two correct.

In the analysis that follows, we depart from the mainstream literature in financial literacy by introducing Precision, Perceived score, and Overestimation as additional explanatory variables to determine how financial literacy and self-perceptions interact with financial decision-making. Since the majority of LinkedIn members appear financially savvy, we also analyze those with lower scores separately.

\subsection{The Demographics of Financial Literacy in LinkedIn}

Table 4 tabulates the proportions of correct responses to the Big 3 and Big 5 questions along with financial literacy scores and beliefs by the demographic background of respondents. We include the results of the 2012 NFCS for the purpose of comparison. Overall, $76 \%$ of LinkedIn respondents answer the Big 3 questions correctly, compared with fewer

than half in the NFCS. Only $38 \%$ of LinkedIn respondents get all five questions correct, but this is more than twice the average that is reported in the NFCS.

Financial literacy is increasing in age, education and income. As in the NFCS, the youngest respondents are the least financially literate in our sample; however, the average score of 25 to 34 year olds in our sample is much higher than that found in the NFCS. Differences between our data and the NFCS are less pronounced as age and income increases, but we still find that our respondents score better than those found in the NFCS in every education category. Table 4 also shows that men are more financially literate than women both in our sample and in the 2012 NFCS; our data show that they have higher overestimation and are more confident about their scores than women. These results therefore support the findings in the previous literature that documents gender differences in self-confidence, such as Barber and Odean (2001).

-Include Table 4 about here- 
Our results are closest to the NFCS among the highest income earners and most educated. This suggests that an important component of the large average difference between our respondents and those found in other studies is attributable to the fact that the prototypical LinkedIn subscriber is a tech-savvy, white-collar working professional. In support for this claim, untabulated results reveal considerably higher average financial literacy scores when we restrict the NFCS sample to only include those who use online banking, where the proportion correctly answering the Big 3 questions rises from 0.37 to 0.45. Still, technological sophistication measured in this way does not eradicate the differences between LinkedIn members and the NFCS. When we compare the same fractions for those with a Bachelor's or Master's degree, we still find that the results from the NFCS are 10 percentage points smaller, and the same is true for all sortings across every income level.

It is possible that these differences capture something unobservable, which goes beyond Internet adaption, income, and education. It is possible that people who sign up for LinkedIn actually display higher financial literacy, or simply pay more attention to the test. Our relatively short survey, with only 22 questions, may also be more successful in eliciting more accurate responses because it places a lower cognitive load on the respondent than the 2012 NFCS, which contains 100 questions.

Table 5 puts the results of the previous tables into a multivariate regression. As found in many previous studies, actual financial literacy score is positively related to age, income, education, but lower for women. ${ }^{13}$ We also find it reassuring that having a finance career is associated with higher financial literacy.

\section{-Include Table 5 about here-}

Turning to the results of our measures of beliefs, we find that women display significantly lower overestimation of their own scores, and they are more uncertain of their scores. These results echo those of Lusardi and Mitchell (2008), who argue that women display less selfconfidence, measured as the propensity to report not knowing the answer, compared to men. High income individuals and those with finance careers are more likely to state

\footnotetext{
${ }^{13}$ Throughout the paper, we only include a linear age term in our specifications. Restricting the sample to those aged 25-64 removes any nonlinear effects of age that are otherwise present in the full sample.
} 
high precision. The university educated display less overestimation and higher precision. Entrepreneurs tend to assign higher scores to the test as well as being more precise. Even if the average score on the financial literacy questions are considerably higher than found in other studies, the cross-sectional variation stand well in comparison with the stylized facts of previous research in both financial literacy and behavioral finance.

\subsection{Financial literacy Scores, Beliefs, and Seniority}

Another way to understand the dispersion in financial literacy and beliefs in our data is to look at the result by job qualification. Table 6 reports demographic traits along with financial literacy measures broken out by self-described employment situation. We find a tilt towards respondents having more senior positions. Around one third of the respondents report having $\mathrm{C}-$ level jobs (CFO, CEO, and $\mathrm{COO})$. On the other hand, we do find representation in a variety of jobs. There are, for instance, 97 students, 128 retirees, 194 currently unemployed, 649 individual contributors, and 458 small business owners in the ages 25 to 64 .

-Include Table 6 about here-

Table 6 shows that both income and education (measured as the fraction of having at least a Bachelor's degree), varies substantially across employment. We also find that age varies with seniority and score of the financial literacy test, where younger, and less senior respondents display lower scores. Executive level employees display the highest average financial literacy but also the highest degree of overestimation and confidence. Perhaps surprisingly, fewer than $60 \%$ of senior-level executives get all five questions correct. Similarly, self-employed individuals and small business owners report higher perceived than actual scores. They also report higher precision in their estimates compared to the average. This squares with the common perception that entrepreneurs are optimistic and overconfident across a wide variety of domains (see, for example, Puri and Robinson (2013)). 


\section{Connecting Beliefs, Financial Literacy and Behaviors}

\subsection{Planning for Retirement}

Retirement planning is one of the cornerstones of long-term household financial security. This has taken on increasing importance across the globe in the wake of many structural changes that shift the responsibility of retirement planning to individuals through the transition from Defined Contribution to Defined Benefit plans. Across the globe, researchers have found a positive correlation between retirement planning and financial literacy. ${ }^{14}$ Lusardi and Mitchell (2007) show that individuals who have planned more for retirement arrive at retirement with higher net worth and savings.

To understand how financial literacy and retirement planning are correlated in our survey, we asked respondents, "Have you tried to figure out how much you need to save for retirement?" Possible answers are "Yes", "No", "Don’t Know", or "Prefer not to say". By framing the question in terms of figuring out retirement rather than actually saving for it, the question is intended to hone in on retirement awareness rather than previous retirement savings, and thereby avoids obvious correlation problems with age and income. Only about $3 \%$ of the sample is non-responsive, and about $75 \%$ of all respondents reported that they had tried to determine this amount.

\section{-Include Table 7 here-}

Column (1) of Table 7 reports results from a Probit model of answering "Yes" to the question above on financial literacy and demographic controls. In keeping with prior literature, Column (1) shows that financial literacy is associated with increased retirement planning, even controlling for income and other demographic controls. Point estimates in Table 7 are reported as marginal effects, so the point estimate indicates that at the mean, getting an additional question correct is associated with about an $8 \%$ higher probability to have contemplated retirement needs. In all specifications, older, higher income respondents are more likely to have saved, as are more educated respondents, and respondents with careers in finance.

\footnotetext{
${ }^{14}$ Van Rooij et al. (2012) show that financial literacy is related to retirement planning in a sample of Dutch households. Bucher-Koenen and Lusardi (2011) finds similar evidence in Germany.
} 
We add our measure of overestimation and precision to the specification in Column (2). When we include beliefs about financial literacy, we find that the effect of actual financial literacy is cut in half. Most of the correlation between retirement planning and financial literacy works through beliefs about one's own financial literacy. Because the loading on Perceived score is larger than that of Actual score, Column (2) indicates that more miscalibrated respondents, not more financially literate ones, are more likely to have thought about how much to save for retirement. Our results indicate that much of the retirement planning decision is driven not by financial literacy itself, but by inaccurate self-perceptions of financial literacy. To gauge the economic significance of this effect, consider only those respondents with an actual score of 3 on the test: only about half of those who thought they scored 2 or below had done retirement calculations, whereas three out of four who thought they scored 4 or higher had done this calculation.

In Column (3), we include dummies for actual financial literacy scores and replace the perceived score with overestimation (the difference between Perceived and Actual score). This addresses the fact that perceived scores among those with perfect actual scores can only reflect underestimation, while perceived scores for those with zero scores can only reflect overestimation. Introducing a dummy for Actual score changes the interpretation of the overestimation variable slightly, because it essentially asks how variation along the $\mathrm{x}$-axis of Figure 3 is correlated with financial decisions. Even after controlling for actual financial literacy non-parametrically, we see that more miscalibrated people are more likely to have thought about their retirement planning needs.

In Columns (4) through (6) we repeat this analysis but focus attention to the set of respondents who got three or fewer questions correct - the low financial literacy sample. There are two reasons for analyzing this subsample: one policy oriented in nature, the other statistical in nature. On the policy front, low financial literacy respondents are presumably those who stand the most to gain by policies aimed at making financial markets friendlier for consumers. On the statistical front, the correlation between actual and perceived literacy is negative for the high financial literacy respondents because the score is bounded from above. Because this runs counter to the overall correlation in the data, it potentially lowers the power of our tests. 
When we focus attention on the low financial literacy sample, we see even stronger results than in Columns (1) through (3). Among low literacy respondents, the link between actual financial literacy is statistically insignificant when we control for Perceived score. Because the point estimate associated with Perceived score is higher than Actual score, when we turn in Column (6) to the direct measure of Overestimation, we again find that more miscalibrated individuals are more like to have planned for retirement.

\subsection{Precautionary Savings Behavior}

Table 8 examines how real and perceived financial literacy is correlated with precautionary savings decisions. The omnibus questionnaire included a question "Have you set aside emergency or rainy day funds that would cover your expenses for 3 months, in case of sickness, job loss, economic downturn, or other emergencies?" Potential answers are "Yes", "No", "Don't Know" and "Prefer not to Say." About two-thirds of respondents report "Yes" to this question, and only a handful prefer not to say. While these fractions are significantly higher than those reported in Lusardi et al. (2011), this difference presumably owes to the large differences in wealth between our sample and others. About half of the respondents in our sample reporting income below $\$ 50,000$ annually have saved, but over two-thirds reporting income levels above that respond affirmatively to this question.

\section{-Include Table 8 here-}

Table 8 presents the results, which echo the findings from the previous subsection. In particular, the effect of actual financial literacy is essentially cut in half when we include perceived financial literacy, and the relative magnitude of the loadings indicates that more miscalibrated individuals, not more financially literate ones, are more likely to have saved.

Specifically, in Column (1) we find that getting one additional question correct on the actual score raises the probability of answering yes to the precautionary savings question by about $8 \%$. In Column (2), we add our measure of overestimation and precision to the specification. When we include beliefs about financial literacy, we find that the effect of actual financial literacy is cut in half. Most of the correlation between precautionary savings and financial literacy works through beliefs about one's own literacy. Our results indicate that much of the propensity to save for a rainy day is driven not by financial 
literacy itself, but by inaccurate self-perceptions. Those who are more miscalibrated are more likely to have set aside funds for a rainy day, and controlling for self-perceptions cuts the effect of actual financial literacy roughly in half.

In Column (3), we include dummies for actual financial literacy scores and replace the perceived score with Overestimation (the difference between perceived and actual score). Again, even after controlling for actual financial literacy non-parametrically, we find that more miscalibrated people are more likely to have saved for a rainy day.

In Columns (4) through (6) again repeats the analysis but focuses attention to the set of respondents who got three or fewer questions correct - the low financial literacy sample. Among low literacy respondents, the connection between financial literacy and precautionary savings is considerably weaker than in the full sample, but its statistical significance disappears entirely when we control for perceptions.

\subsection{Who Makes Investment Decisions in the Household?}

Although precautionary savings and retirement planning are two of the most important facets of financial decision-making faced by most households, focusing only on these behaviors may lead to an incomplete picture of the connection between financial literacy and household financial decision-making. For instance, the framing of the retirement planning question incorporates the possibility that someone has thought about the problem, but does not know how to take action. For precautionary savings, it may or may not be optimal from a utility maximization point of view to set aside funds for the future, especially for very low income individuals. At the other end of the spectrum, some individuals with high, steady income might have ready access to abundant liquidity in case of hardship, and thus might have little need to use traditional savings vehicles.

To deal with these possibilities we expand our measure of financial behavior by adding one question onto the survey. One of the simplest measures of financial sophistication is whether someone is responsible for financial decisions in their home or whether instead this is delegated to someone else. We connect the degree of actual and perceived financial literacy to whether someone has sole responsibility for financial investment decision-making in their household as a way of measuring behavior that is robust to the caveats laid out above. In the second wave, our survey asks "Which of the following best describes your role 
in making financial investment decisions?" Answers are "I am the primary . . .", "I share responsibility", and "Someone else in the family makes financial investment decisions."

These results are presented in Table 9. The table reports Probit regressions where the dependent variable takes the value of one if the response to the question is "I am the primary decision maker in the household. The results in Column (1) reveal that household decision-makers are more likely to be young and work in finance. Among LinkedIn users, women are less likely to be sole investment decision-makers in the household. Income is negatively correlated with sole investment decision-making, which presumably reflects a combination of the fact that high-earning individuals have both significant time constraints and more complicated investment decisions.

-Include Table 9 here-

Column (2) shows that the connection between actual financial literacy and household financial decision-making loses statistical significance when we include our measure of perceived financial literacy. In a horse-race between actual and perceived score, perceptions of literacy drive out actual financial literacy. Put differently, the comparison of the two point estimates on actual and perceived financial literacy indicates that those who think they are more literate than they actually are are the respondents most likely to have responsibility for their home finances. In Column (3), we include dummies for each level of score, and again find that overestimation remain strongly significant

In Columns (4) through (6), we focus on the low financial literacy sample, but with considerable fewer observations than in the previous tables. Still, actual score along with income and finance career is statistically significantly related to having sole decision responsibility. When we include beliefs in Columns (5) and (6), the results are very similar to those of the full sample. Holding constant actual financial literacy, those who think they are more literate are much more likely to be decision-makers.

While these results comport with our analysis of precautionary savings and retirement planning, it is important to acknowledge a number of serious challenges associated with using household financial investment decision-making as a dependent variable. Concerns with reverse causality are likely to be severe here, as someone tasked with making financial 
decisions may as a result actively seek out and acquire financial knowledge. Moreover, we have life cycle savings models to guide our analysis of retirement planning and precautionary savings, but we have no such models to predict whether someone should or should not be a household financial decision-maker. A more traditional approach would simply be to control for whether an individual was a decision-maker when running regressions connecting financial literacy, precautionary savings and retirement planning. Indeed, all the results in this paper are robust to such a filter. Nevertheless, with these caveats notwithstanding, the correlation we observe between beliefs, literacy and household financial decision-making provides further support for the idea that beliefs are an important mechanism through which decision-making and financial literacy are connected. ${ }^{15}$

\subsection{Robustness checks}

In untabulated results, we find that our analysis remains unchanged when controlling for the time spent on completing the survey, as well as including dummies for job seniority (see Table 6). We obtain very similar results when using OLS in place of those reported from a Probit model. We also ran the regressions in Table 7 through 9 separately for women only, and those with college education or having income below $\$ 50,000$. Overestimation is significant for all specifications except household decision-making, but here the sample is also considerably smaller.

In order to further investigate if our results are indeed driven by respondents not knowing the correct answer, we repeat the analysis as in Table 7 through Table 9, but in which we treat the response "Don't know" as a correct answer when counting scores on the financial literacy test. As we obtain similar results, we conclude that is mainly the the variation stemming from responding that you think you know the right answer that explains our results, not stating that you do not know. In another specification, we also opted to include the number of "Don't know" responses separately along with our explanatory variables in the regressions above, all in which the coefficient for Overestimation remains strongly significant.

\footnotetext{
${ }^{15}$ We thank the referee for pointing out these issues.
} 


\section{Informed Choice and Financial Advice}

The results so far indicate that while respondents are well calibrated on average, there is substantial cross-sectional variation in both real and perceived financial literacy, and that perceptions more than reality drive important financial planning decisions. In this section we ask whether these mistaken beliefs that seem so important for financial planning are likely to be good or bad for the people who harbor them.

In the second wave of data collection, we added a question to gauge whether respondents were aware of common advice about financial markets:

- When selecting a mutual fund, it is generally more important to consider past performance of the fund than it is to consider the management charges. Please select one.

(a) Agree $[N=1,188]$

(b) Disagree $[N=967]$

(c) Don't know $[N=659]$

(d) Prefer not to say $[N=68]$

The wording of this question closely mirrors the language that policymakers use in attempts to make investors aware of the implication of fees and how to invest wisely. For example, the U.S. Securities and Exchange Commission's website Investor.gov advises users to pay attention to fees using almost identical language. ${ }^{16}$ The correct answer to this question according to most sources is to focus on fees, not past performance. In fact, a larger number of respondents answer "Agree," indicating that they think past performance is more important than management fees. This is maybe particular striking considering that the responses come from a pool of mainly white collar, college educated, high income earners.

-Include Table 10 here-

In Table 10 we explore how the answers to this question relate to overestimation. Holding constant the actual literacy score with fixed effects for number correct, a one standard

\footnotetext{
${ }^{16}$ See http://investor.gov/investing-basics/investment-products/mutual-funds\#Fees .
} 
deviation spread in Overestimation induces a $6 \%$ lower probability of responding that they do not know the answer to the question. Given that about $23 \%$ of the sample does not know the answer, this effect is large. Yet in Column (2) when we run a Probit that equals 1 if the respondent got the answer wrong, 0 otherwise, we find that more miscalibrated respondents are about $2 \%$ more likely to get the answer wrong. Thus, believing that one is more financially literate than they actually are is associated with more certainty but less accuracy about domains of financial literacy not captured by the Big 5 .

To push this further, we make use of questions that measure willing to accept advice. Accessing and acting on financial advice has been shown to be one method by which financially literate households plan and prepare for future events like retirement (Lusardi and Mitchell, 2011). In particular, our survey included the question "How satisfied or dissatisfied would you be if financial planning advice or information (e.g. articles, videos, infographics) occasionally appeared in your LinkedIn news stream?" Responses included "Very satisfied", "Somewhat satisfied", "Neither satisfied nor unsatisfied", "Somewhat dissatisfied", "Very dissatisfied", and "Don't know" or "Prefer not to say".

LinkedIn may not be perceived as a natural provider of financial advice by many respondents, nevertheless the context in which the question is being asked is important to consider: this is being asked to a sample of active LinkedIn members who in turn have actively self-selected into taking the survey. They are therefore much more likely to have a positive view on LinkedIn and the services they provide compared to people in general.

Column (3) of Table 10 tabulates the results from a Probit regression where the dependent variable takes the value one if the respondent reported being somewhat or very dissatisfied with receiving advice. We find that respondents who overestimate their scores are more likely to avoid advice. This is a problematic finding from a policy perspective because prior work has demonstrated that more financially literate people are more likely to use advisors to help with financial planning tasks.

One possible concern about this conclusion is that high income earners, which are over-represented in our sample, are more likely to possess skills to manage their personal finances, or already have established channels for doing so. Therefore, a reluctance to receive advice can well be driven by the fact that affluent people are less likely to find 
information on LinkedIn very useful. If the same people also tend to overestimate their financial knowledge, we are likely to overstate the reluctance to accept advice.

To meet this concern, we exclude those with an annual income above $\$ 100,000$. A motivation for choosing this cut-off is found in Table 2, which reveals that the group earning more than that is overrepresented in our sample compared to the U.S. population, and so can of course be important in driving the overall result.

Column (4) of Table 10 report the results, where we find some evidence of this, since the coefficient for Overestimation remain significant, but drops by more than one quarter when we exclude the most affluent respondents. When we cut income at lower levels, we lose statistical power, even though the point estimate remain positive.

Our results confirm that the negative relation between self-perceptions and willingness to accept advice is not only driven by those who likely have other sources of financial information among LinkedIn members. In conjunction with the mistaken beliefs about mutual funds, this suggests that mistaken beliefs about financial literacy can be as problematic as low literacy itself.

\section{Summary and Conclusions}

Financial literacy has been placed front and center in policy discussions attempting to reform retail financial markets in the wake of the financial crisis. A growing consensus suggests that Americans have low financial literacy, and that this in turn is associated with low levels of participation in the kinds of planning and savings decisions that are needed to build a sound financial future. We study these issues using a novel dataset of largely tech-savvy, white collar professionals who use the LinkedIn professional networking website.

We find that the link between financial literacy, precautionary savings, and retirement planning hinges critically on self-perceptions. Savers and planners are those who believe they are financially informed, not necessarily those who are informed. Mistaken beliefs about financial literacy are as important as actual financial literacy itself.

Thus, our results heap more trouble onto the plate of policy makers who are interested in improving literacy in order to facilitate household financial planning and savings. Our findings indicate that mistaken beliefs about financial literacy may be as problematic as 
financial illiteracy itself. And this occurs in a sample where individuals score about twice as high in financial literacy on average than previous studies have found.

It is important to stress the descriptive nature of our findings. Our results do not show that mistaken beliefs cause people to save or plan for retirement. Indeed, a fascinating possibility is that taking up these decisions causes mistaken beliefs. Under this explanation for the observed correlation between beliefs and these behaviors, small amounts of variation in the initial level of overconfidence or optimism could cause individuals to participate in financial decisions, while their planning and savings activity could in turn create a type of learning-by-doing that both imparts literacy but also amplifies self-perceptions. Understanding how beliefs, literacy and financial planning behaviors play out in a dynamic context over the life cycle is a fascinating and important area for future work.

Our findings suggest that there is much more to be learned about household financial decision-making by the ongoing work that incorporates findings from behavioral psychology and economics into studies of household finance. Planning effectively for retirement requires making long-range planning decisions, which by their very nature, offer feedback at low frequencies. Understanding how behavioral biases affect these decisions is an important question for future research. 
Allgood, S., Walstad, W.B., 2012. The effects of perceived and actual financial literacy on financial behaviors. National Financial Capability Study Roundtable, The George Washington School of Business.

Ameriks, J., Caplin, A., Leahy, J., 2003. Wealth accumulation and the propensity to plan. Quarterly Journal of Economics 118, 1007-47.

Barber, B.M., Odean, T., 2000. Trading is hazardous to your wealth: The common stock investment performance of individual investors. Journal of Finance 60, 773-806.

Barber, B.M., Odean, T., 2001. Boys will be boys: Gender, overconfidence, and common stock investment. Quarterly Journal of Economics 116, 261-92.

Bucher-Koenen, T., Lusardi, A., 2011. Financial literacy and retirement planning in Germany. Journal of Pension Economics and Finance 10, 565-84.

Camerer, C., Lovallo, D., 1999. Overconfidence and excess entry: An experimental approach. American Economic Review 89, 306-18.

Hastings, J.S., Madrian, B.C., Skimmyhorn, W.L., 2013. Financial literacy, financial education, and economic outcomes. Annual Review of Economics 5, 347-73.

Hilgert, M.H., Hogarth, J.M., Beverly, S.G., 2003. Household financial management: The connection between knowledge and behavior. Annual Review of Economics 89, 309-22.

Hong, H., Kubik, J.D., Stein, J.C., 2004. Social interaction and stock-market participation. Journal of Finance 59, 137-63.

Kruger, J., Dunning, D., 1999. Unskilled and unaware of it: How difficulties in recognizing one's own incompetence lead to inflated self-assessments. Journal of Personality and Social Psychology 77, 1121-34.

Lichtenstein, S., Fischhoff, B., Phillips, L.D., 1982. Calibration of probabilities: The state of the art to 1980, in: Kahneman, D., Slovic, P., Tversky, A. (Eds.), Judgement under Uncertainty: Heuristics and Biases. Cambridge University Press, Cambridge, M.A., pp. $306-34$.

Lusardi, A., Mitchell, O.S., 2005. Financial literacy and planning: Implications for retirement wellbeing. Michigan Retirement Research Center, WP 2015-108.

Lusardi, A., Mitchell, O.S., 2007. Baby boomer retirement security: The roles of planning, financial literacy, and housing wealth. Journal of Monetary Economics 54, 205-24.

Lusardi, A., Mitchell, O.S., 2008. Planning and financial literacy: How do women fare? American Economic Review 98, 413-7.

Lusardi, A., Mitchell, O.S., 2009. How ordinary consumers make complex economic decisions: Financial literacy and retirement readiness. National Bureau of Economic Research Working Paper 15350. 
Lusardi, A., Mitchell, O.S., 2011a. Financial literacy and retirement planning in the United States. Journal of Pension Economics and Finance 10, 497-508.

Lusardi, A., Mitchell, O.S., 2011b. Financial literacy around the world: An overview. Journal of Pension Economics and Finance 10, 497-508.

Lusardi, A., Mitchell, O.S., 2014. The economic importance of financial literacy: Theory and evidence. Journal of Economic Literature 52, 5-44.

Lusardi, A., Schneider, D.J., Tufano, P., 2011. Financially fragile households: Evidence and implications, in: Romer, D.H., Wolfers, J. (Eds.), Brookings Papers on Economic Activity. Brookings Institution Press, Washington, D.C., pp. 83 - 134.

Moore, D., Healy, P.J., 2008. The trouble with overconfidence. Psychological Review 115, $502-17$.

Parker, A.M., de Bruin, W.B., Yoong, J., Willis, R., 2012. Inappropriate confidence and retirement planning: Four studies with a national sample. Journal of Behavioral Decision Making 25, 382-9.

Puri, M., Robinson, D.T., 2007. Optimism and economic choice. Journal of Financial Economics 86, 71-99.

Puri, M., Robinson, D.T., 2013. The economic psychology of entrepreneurship and family business. Journal of Economics and Management Strategy 22, 423-44.

Shiller, R.J., 1999. Human behavior and the efficiency of the financial system, in: Taylor, J.B., Woodward, M. (Eds.), Handbook of Macroeconomics. Elsevier Science, Netherlands, pp. 1305-40.

Van Rooij, M., Lusardi, A., Alessie, R., 2011. Financial literacy and stock market participation. Journal of Financial Economics 191, 449-72.

Van Rooij, M., Lusardi, A., Alessie, R., 2012. Financial literacy, retirement planning and household wealth. Economic Journal 122, 449-78. 


\section{Table 1: The Big 5 Financial Literacy Questions}

This table presents the five financial literacy questions used in this paper taken from two previous surveys. The first three ("Big 3" ) questions appear in the 2004 Health and Retirement Study. The two last questions were added to the first three in the 2009 and 2012 National Financial Capability Survey, and collectively referred to as the "Big 5".

1. Compounding. Suppose you had $\$ 100$ in a savings account and the interest rate was $2 \%$ per year. After 5 years, how much do you think you would have in the account if you left the money to grow? Please select one.

- More than $\$ 102$

- Exactly $\$ 102$

- Less than $\$ 102$

- Don't know

- Prefer not to say

2. Inflation. Imagine that the interest rate on your savings account was $1 \%$ per year and inflation was $2 \%$ per year. After 1 year, how much would you be able to buy with the money in this account? Please select one.

- More than today

- Exactly the same as today

- Less than today

- Don't know

- Prefer not to say

3. Diversification. Buying a single companys stock usually provides a safer return than a stock mutual fund. Please select one.

- True

- False

- Don't know

- Prefer not to say

4. Mortgage. A 15-year mortgage typically requires higher monthly payments than a 30-year mortgage, but the total interest paid over the life of the loan will be less. Please select one.

- True

- False

- Don't know

- Prefer not to say

5. Bond Pricing. If interest rates fall, what should happen to bond prices? Please select one.

- They will rise

- They will fall

- They will stay the same

- There is not relationship between bond prices and the interest rate

- Don't know

- Prefer not to say 


\section{Table 2: The Demographics of LinkedIn Respondents}

This table presents summary statistics on the demographics of the full sample of 5,814 survey respondents. Wave 1 corresponds to averages and sample proportions for the 2,393 responses in the wave conducted in January, 2014. Wave 2 refers to the 3,421 responses in the survey conducted in July, 2014. The column labeled "NFCS" corresponds to sample averages and proportions from 25,509 responses to the 2012 State-by-State National Financial Capability Survey. The column labeled "U.S. Pop." reports corresponding values from the 2013 U.S. Census Bureau Income Survey with 122,459 observations.

\section{Wave 1 Wave 2 Total NFCS $\quad$ U.S. Pop.}

\section{Gender}

Male

0.66

0.64

0.65

0.45

0.49

Female

0.34

0.36

0.35

0.55

0.51

$\begin{array}{llllll}\text { Age } & & & & & \\ 18-24 & 0.07 & 0.06 & 0.06 & 0.10 & 0.05 \\ 25-34 & 0.18 & 0.18 & 0.18 & 0.17 & 0.16 \\ 35-44 & 0.18 & 0.20 & 0.19 & 0.17 & 0.18 \\ 45-54 & 0.26 & 0.23 & 0.24 & 0.20 & 0.20 \\ 55-64 & 0.21 & 0.23 & 0.22 & 0.19 & 0.19 \\ 65 \text { or Older } & 0.09 & 0.10 & 0.10 & 0.17 & 0.22\end{array}$

Education

Bachelor's

0.32

0.32

0.32

0.21

0.19

Master's \& PhD's

0.33

0.34

0.33

0.13

0.12

Income

Less than $15 \mathrm{~K}$

0.03

0.02

0.02

0.13

0.14

$15 \mathrm{~K}-24 \mathrm{~K}$

0.03

0.02

0.02

0.12

0.12

$25 \mathrm{~K}-34 \mathrm{~K}$

0.03

0.03

0.03

0.11

0.11

$35 \mathrm{~K}-49 \mathrm{~K}$

0.07

0.07

0.07

0.15

0.14

$50 \mathrm{~K}-74 \mathrm{~K}$

0.14

0.13

0.13

0.19

0.18

$75 \mathrm{~K}-99 \mathrm{~K}$

0.13

0.14

0.14

0.12

0.12

100K-149K

0.20

0.21

0.20

0.11

0.12

More than $150 \mathrm{~K}$

0.24

0.24

0.24

0.07

0.09

\section{Profession}

Finance

0.12

0.12

0.12

Entrepreneur

0.17

0.17

0.17

0.08 
Table 3: Perceived Score, Overestimation, and Precision across Actual Score

This table presents means and correlations for key variables for respondents aged 25-64. Perceived score is the expected number of correct answers on the literacy test, where subjective probability weights are used to compute the expectation: formally, this is $\sum_{0}^{5} I_{j} p_{j}$, where $I_{j}$ is an indicator associated with getting $j \in[0,5]$ correct answers on the test, and $p_{j}$ is the subjective probability the respondent attaches to getting that many correct. Overestimation is the difference between Actual and Perceived score. Precision ranges from 0 to 1 and is computed as the sum of the squared probability weights assigned to each potential number of correct answers, or $\sum_{0}^{5} p_{j}^{2}$. "Proportion Sure" reports the fraction of respondents giving the full weight to one outcome only $\left(p_{j}=1\right.$ for some $j$ ), broken out separately for whether they were correct or incorrect in this assessment. Panel A provides averages grouped according to the actual number of correct items. The final column in Panel A provides the number of respondents overall $(4,896)$ as well as the number with certain score ranges. Panel B provides correlations between key variables.

\begin{tabular}{|c|c|c|c|c|c|c|c|c|}
\hline & \multicolumn{4}{|c|}{ Averages } & \multirow{2}{*}{\multicolumn{3}{|c|}{$\begin{array}{c}\text { Proportion Sure } \\
(\text { Precision }=1)\end{array}$}} & \multirow[b]{3}{*}{$\mathrm{N}$} \\
\hline & \multirow[b]{2}{*}{ Actual } & \multirow{2}{*}{$\begin{array}{c}\text { Per- } \\
\text { ceived }\end{array}$} & \multirow{2}{*}{$\begin{array}{c}\text { Over- } \\
\text { estimation }\end{array}$} & \multirow{2}{*}{$\begin{array}{l}\text { Pre- } \\
\text { cision }\end{array}$} & & & & \\
\hline & & & & & All & Correct & Incorrect & \\
\hline Overall Me & 4.09 & 4.00 & -0.08 & 0.69 & 0.32 & 0.20 & 0.12 & 4,896 \\
\hline
\end{tabular}

Panel A: Means by Actual Answers Correct

\begin{tabular}{lccccccr} 
All Five Correct & 4.56 & -0.44 & 0.79 & 0.44 & 0.40 & 0.04 & 1,847 \\
Four Questions Correct & 3.98 & -0.02 & 0.65 & 0.25 & 0.08 & 0.17 & 2,022 \\
Three Questions Correct & 3.29 & 0.29 & 0.59 & 0.24 & 0.08 & 0.16 & 713 \\
Two or Fewer Correct & 2.53 & 0.79 & 0.58 & 0.27 & 0.07 & 0.19 & 314 \\
& & & & & & & \\
Panel B: Correlations & & & & & & \\
Actual & 0.58 & -0.39 & 0.26 & 0.15 & 0.30 & -0.16 \\
Perceived & 1.00 & 0.53 & 0.53 & 0.31 & 0.32 & 0.06 \\
Overestimation & & 1.00 & 0.33 & 0.20 & 0.05 & 0.23 \\
Precision & & & 1.00 & 0.78 & 0.56 & 0.42 \\
Sure All & & & & 1.00 & 0.73 & 0.54 \\
Sure Right & & & & & 1.00 & -0.19 \\
Sure Wrong & & & & & & 1.00 & \\
\hline
\end{tabular}


Table 4: The Demographics of Financial Literacy

This table reports the proportion of the total 4,896 respondents aged 25-64 with correct scores, broken out by the demographics reported in Table 2. Columns labeled "LinkedIn"" correspond to the sample proportions of each row correctly answering the "Big 3" (questions on compounding, inflation, and diversification); and "Big 5" (adds the questions on bond prices and mortgages). The corresponding results from the 2012 State-by-State NFCS are reported in the columns labeled "NFCS" based on 18,147 responses from respondents of the same age group. The last three columns report the LinkedIn sample averages of Actual score, Perceived score, and Precision. Precision is calculated as $\sum_{0}^{5}\left(p_{j}\right)^{2}$, where $j$ subscripts the number of correct answers. This measures how tightly the distribution of beliefs is centered around the modal response.

\begin{tabular}{|c|c|c|c|c|c|c|c|}
\hline & \multicolumn{4}{|c|}{ Proportion Correct } & \multirow{2}{*}{\multicolumn{3}{|c|}{ Average Scores }} \\
\hline & \multicolumn{2}{|c|}{ Big 3} & \multicolumn{2}{|c|}{ Big 5} & & & \\
\hline & LinkedIn & NFCS & LinkedIn & NFCS & Actual & Percieved & Precision \\
\hline Overall & 0.76 & 0.37 & 0.38 & 0.16 & 4.09 & 4.00 & 0.69 \\
\hline \multicolumn{8}{|l|}{ Gender } \\
\hline Male & 0.83 & 0.49 & 0.45 & 0.22 & 4.27 & 4.25 & 0.73 \\
\hline Female & 0.63 & 0.28 & 0.25 & 0.10 & 3.77 & 3.57 & 0.62 \\
\hline \multicolumn{8}{|l|}{ Age } \\
\hline $25-34$ & 0.70 & 0.25 & 0.30 & 0.08 & 3.89 & 3.73 & 0.60 \\
\hline $35-44$ & 0.73 & 0.36 & 0.34 & 0.14 & 4.01 & 3.92 & 0.67 \\
\hline $45-54$ & 0.77 & 0.40 & 0.39 & 0.17 & 4.14 & 4.06 & 0.71 \\
\hline $55-64$ & 0.81 & 0.46 & 0.46 & 0.22 & 4.26 & 4.24 & 0.76 \\
\hline \multicolumn{8}{|l|}{ Education } \\
\hline Bachelor's & 0.77 & 0.48 & 0.39 & 0.23 & 4.13 & 4.03 & 0.68 \\
\hline Master's \& PhD's & 0.79 & 0.62 & 0.44 & 0.33 & 4.20 & 4.08 & 0.69 \\
\hline \multicolumn{8}{|l|}{ Income } \\
\hline Less than $15 \mathrm{~K}$ & 0.55 & 0.16 & 0.19 & 0.04 & 3.40 & 3.36 & 0.56 \\
\hline $15 \mathrm{~K}-24 \mathrm{~K}$ & 0.51 & 0.22 & 0.18 & 0.06 & 3.41 & 3.30 & 0.58 \\
\hline $25 \mathrm{~K}-34 \mathrm{~K}$ & 0.59 & 0.25 & 0.21 & 0.09 & 3.62 & 3.33 & 0.58 \\
\hline $35 \mathrm{~K}-49 \mathrm{~K}$ & 0.55 & 0.33 & 0.22 & 0.11 & 3.60 & 3.49 & 0.58 \\
\hline $50 \mathrm{~K}-74 \mathrm{~K}$ & 0.67 & 0.39 & 0.25 & 0.15 & 3.84 & 3.72 & 0.63 \\
\hline $75 \mathrm{~K}-99 \mathrm{~K}$ & 0.74 & 0.50 & 0.31 & 0.23 & 4.01 & 3.87 & 0.68 \\
\hline $100 \mathrm{~K}-149 \mathrm{~K}$ & 0.80 & 0.56 & 0.39 & 0.27 & 4.17 & 4.09 & 0.70 \\
\hline More than $150 \mathrm{~K}$ & 0.87 & 0.66 & 0.52 & 0.39 & 4.40 & 4.34 & 0.75 \\
\hline \multicolumn{8}{|l|}{ Profession } \\
\hline Finance & 0.81 & . & 0.52 & 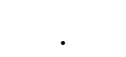 & 4.33 & 4.27 & 0.76 \\
\hline Entrepreneur & 0.79 & 0.45 & 0.43 & 0.20 & 4.20 & 4.22 & 0.73 \\
\hline
\end{tabular}


Table 5: Demographics, Financial Literacy, and Self-Assessed Measures of Performance

This table reports OLS regressions of the key variables of interest on demographic variables. "Actual Score" records the number of "Big 5" questions answered correctly. Overestimation is the difference between the respondent's subjective mean score and their actual score. Precision is calculated as $\sum_{0}^{5}\left(p_{j}\right)^{2}$, where $j$ subscripts the number of correct answers. This measures how tightly the distribution of beliefs is centered around the modal response.

\begin{tabular}{lccc}
\hline \multirow{2}{*}{ VARIABLES } & $(1)$ & $(2)$ & $(3)$ \\
Age & Actual Score & Overestimation & Precision \\
Female & $0.013^{* * *}$ & $0.003^{* * *}$ & $0.005^{* * *}$ \\
& $(0.001)$ & $(0.001)$ & $(0.000)$ \\
ln(Income) & $-0.466^{* * *}$ & $-0.180^{* * *}$ & $-0.095^{* * *}$ \\
& $(0.028)$ & $(0.028)$ & $(0.008)$ \\
Finance Career & $0.093^{* * *}$ & -0.018 & $0.010^{* * *}$ \\
& $(0.011)$ & $(0.011)$ & $(0.003)$ \\
Degree & $0.243^{* * *}$ & 0.031 & $0.077^{* * *}$ \\
& $(0.036)$ & $(0.035)$ & $(0.011)$ \\
Entrepreneur & $0.308^{* * *}$ & $-0.059^{* *}$ & $0.018^{* *}$ \\
& $(0.028)$ & $(0.029)$ & $(0.008)$ \\
Constant & $0.070^{* *}$ & $0.085^{* * *}$ & $0.020^{* *}$ \\
& $(0.032)$ & $(0.032)$ & $(0.010)$ \\
& $3.007^{* * *}$ & -0.062 & $0.429^{* * *}$ \\
Observations & $(0.083)$ & $(0.081)$ & $(0.023)$ \\
R-squared & 4,896 & 4,896 & 4,896 \\
\hline
\end{tabular}

Robust standard errors in parentheses

*** $\mathrm{p}<0.01,{ }^{* *} \mathrm{p}<0.05,{ }^{*} \mathrm{p}<0.1$ 


\section{Table 6: Financial Literacy and Employment Experience}

This table presents summary statistics of key demographic and financial literacy variables based on the self-reported employment status of survey respondents. Income is reported in thousands and is based on taking the midpoints of the ranges listed in Table 2. Perceived score is the expected number of correct answers on the financial literacy test, where subjective probability weights are used to compute the expectation: formally, this is $\sum_{0}^{5} I_{j} p_{j}$, where $I_{j}$ is an indicator associated with getting $j \in[0,5]$ correct answers on the test. Precision ranges from 0 to 1 and is computed as the sum of the squared probability weights assigned to each potential number of correct answers, or $\sum_{0}^{5} p_{j}^{2}$.

\begin{tabular}{lccccccccc}
\hline & & & & & & \multicolumn{5}{c}{ Literacy Score } \\
\cline { 7 - 9 } & $\mathrm{N}$ & Age & Female & Income & Degree & \% Big 5 & Actual & Perceived Precision \\
\hline Student & 97 & 31.90 & 0.54 & 39.58 & 0.88 & 0.26 & 3.71 & 3.63 & 0.57 \\
Individual contributor & 649 & 39.97 & 0.51 & 80.64 & 0.68 & 0.27 & 3.85 & 3.63 & 0.60 \\
Senior individual contributor & 799 & 43.66 & 0.32 & 108.66 & 0.69 & 0.36 & 4.14 & 4.04 & 0.69 \\
Manager or equivalent & 741 & 43.49 & 0.35 & 107.03 & 0.64 & 0.35 & 4.02 & 3.95 & 0.68 \\
Senior Manager or equivalent & 354 & 46.07 & 0.27 & 127.17 & 0.65 & 0.38 & 4.16 & 4.01 & 0.69 \\
Director or equivalent & 395 & 45.52 & 0.39 & 152.46 & 0.73 & 0.43 & 4.20 & 4.07 & 0.70 \\
Dept. Head, VP or Equiv & 310 & 48.16 & 0.26 & 170.41 & 0.76 & 0.48 & 4.30 & 4.27 & 0.75 \\
Pres., Man. Dir., or Equiv & 128 & 52.40 & 0.24 & 217.87 & 0.62 & 0.48 & 4.31 & 4.36 & 0.79 \\
C-Level Exec. or Equiv & 102 & 49.57 & 0.19 & 241.43 & 0.75 & 0.59 & 4.44 & 4.35 & 0.79 \\
Small Business Owner & 458 & 49.69 & 0.26 & 160.27 & 0.61 & 0.46 & 4.31 & 4.32 & 0.75 \\
Self-employed & 374 & 50.38 & 0.43 & 93.34 & 0.62 & 0.39 & 4.07 & 4.09 & 0.71 \\
I am retired & 128 & 59.96 & 0.23 & 92.07 & 0.44 & 0.38 & 4.13 & 4.25 & 0.75 \\
Other & 167 & 45.93 & 0.58 & 85.09 & 0.55 & 0.28 & 3.65 & 3.55 & 0.64 \\
I am not currently employed & 194 & 45.64 & 0.45 & 70.97 & 0.66 & 0.35 & 3.93 & 3.83 & 0.68
\end{tabular}


Table 7: Retirement Planning, Real and Perceived Financial Literacy

This table presents Probit regressions modeling the probability that the respondent answered "Yes" to the question, "Have you ever tried to figure out how much you need to save for your retirement?" Independent variables are defined in Table 2. Point estimates are reported as marginal probabilities. Columns (1) through (3) report results from the whole sample; Columns (4) through (6) from the low-financial literacy subsample, excluding those with scores higher than 3.

\begin{tabular}{|c|c|c|c|c|c|c|}
\hline VARIABLES & (1) & $(2)$ & $(3)$ & $(4)$ & $(5)$ & (6) \\
\hline Actual Score & $\begin{array}{c}0.082^{* * *} \\
(0.007)\end{array}$ & $\begin{array}{c}0.044^{* * *} \\
(0.008)\end{array}$ & & $\begin{array}{c}0.070^{* * *} \\
(0.024)\end{array}$ & $\begin{array}{c}0.037 \\
(0.026)\end{array}$ & \\
\hline Perceived Score & & $\begin{array}{c}0.069^{* * *} \\
(0.008)\end{array}$ & & & $\begin{array}{c}0.062^{* * *} \\
(0.016)\end{array}$ & \\
\hline Precision & & $\begin{array}{c}0.014 \\
(0.026)\end{array}$ & & & $\begin{array}{l}-0.002 \\
(0.056)\end{array}$ & \\
\hline Overestimation & & & $\begin{array}{c}0.072^{* * *} \\
(0.008)\end{array}$ & & & $\begin{array}{c}0.064^{* * *} \\
(0.016)\end{array}$ \\
\hline Age & $\begin{array}{c}0.006^{* * *} \\
(0.001)\end{array}$ & $\begin{array}{c}0.006^{* * *} \\
(0.001)\end{array}$ & $\begin{array}{c}0.006^{* * *} \\
(0.001)\end{array}$ & $\begin{array}{c}0.009^{* * *} \\
(0.002)\end{array}$ & $\begin{array}{c}0.009^{* * *} \\
(0.002)\end{array}$ & $\begin{array}{c}0.009 * * * \\
(0.002)\end{array}$ \\
\hline Female & $\begin{array}{l}-0.010 \\
(0.013)\end{array}$ & $\begin{array}{c}0.019 \\
(0.013)\end{array}$ & $\begin{array}{c}0.019 \\
(0.013)\end{array}$ & $\begin{array}{l}-0.027 \\
(0.033)\end{array}$ & $\begin{array}{c}0.003 \\
(0.033)\end{array}$ & $\begin{array}{c}0.000 \\
(0.034)\end{array}$ \\
\hline $\ln ($ Income $)$ & $\begin{array}{c}0.028^{* * *} \\
(0.005)\end{array}$ & $\begin{array}{c}0.026^{* * *} \\
(0.005)\end{array}$ & $\begin{array}{c}0.026^{* * *} \\
(0.005)\end{array}$ & $\begin{array}{c}0.059^{* * *} \\
(0.015)\end{array}$ & $\begin{array}{c}0.062^{* * *} \\
(0.015)\end{array}$ & $\begin{array}{c}0.060 * * * \\
(0.015)\end{array}$ \\
\hline Finance Career & $\begin{array}{c}0.062^{* * *} \\
(0.018)\end{array}$ & $\begin{array}{c}0.053^{* * *} \\
(0.018)\end{array}$ & $\begin{array}{c}0.051^{* * *} \\
(0.018)\end{array}$ & $\begin{array}{c}0.120^{* *} \\
(0.053)\end{array}$ & $\begin{array}{c}0.114^{* *} \\
(0.053)\end{array}$ & $\begin{array}{l}0.104^{*} \\
(0.054)\end{array}$ \\
\hline Degree & $\begin{array}{c}0.049^{* * *} \\
(0.014)\end{array}$ & $\begin{array}{c}0.043^{* * *} \\
(0.014)\end{array}$ & $\begin{array}{c}0.042^{* * *} \\
(0.014)\end{array}$ & $\begin{array}{c}0.050 \\
(0.033)\end{array}$ & $\begin{array}{c}0.047 \\
(0.034)\end{array}$ & $\begin{array}{c}0.047 \\
(0.034)\end{array}$ \\
\hline Entrepreneur & $\begin{array}{c}0.006 \\
(0.017)\end{array}$ & $\begin{array}{l}-0.004 \\
(0.017)\end{array}$ & $\begin{array}{l}-0.003 \\
(0.017)\end{array}$ & $\begin{array}{l}-0.030 \\
(0.047)\end{array}$ & $\begin{array}{l}-0.038 \\
(0.047)\end{array}$ & $\begin{array}{l}-0.039 \\
(0.047)\end{array}$ \\
\hline $\begin{array}{l}\text { Observations } \\
\text { Literacy dummies } \\
\text { Pseudo } \mathrm{R}^{2}\end{array}$ & $\begin{array}{c}4,896 \\
\text { No } \\
0.0762\end{array}$ & $\begin{array}{c}4,896 \\
\text { No } \\
0.0933\end{array}$ & $\begin{array}{c}4,896 \\
\text { Yes } \\
0.0952\end{array}$ & $\begin{array}{c}1,027 \\
\text { No } \\
0.0531\end{array}$ & $\begin{array}{c}1,027 \\
\text { No } \\
0.0644\end{array}$ & $\begin{array}{c}1,027 \\
\text { Yes } \\
0.0697\end{array}$ \\
\hline
\end{tabular}

Robust standard errors in parentheses

*** $\mathrm{p}<0.01, * * \mathrm{p}<0.05,{ }^{*} \mathrm{p}<0.1$ 


\title{
Table 8: Precautionary Saving and Perceptions of Financial Literacy
}

\begin{abstract}
This table presents Probit regressions modeling the probability that the respondent answered "Yes" to the question, "Have you set aside emergency or rainy day funds that would cover your expenses for 3 months, in case of sickness, job loss, economic downturn, or other emergencies?". Independent variables are defined in Table 2. Point estimates are reported as marginal probabilities. Columns (1) through (3) report results from the whole sample; Columns (4) through (6) from the low-financial literacy subsample, excluding those with scores higher than 3.
\end{abstract}

\begin{tabular}{|c|c|c|c|c|c|c|}
\hline VARIABLES & (1) & $(2)$ & (3) & (4) & $(5)$ & (6) \\
\hline Actual Score & $\begin{array}{c}0.084^{* * *} \\
(0.008)\end{array}$ & $\begin{array}{c}0.044^{* * *} \\
(0.009)\end{array}$ & & $\begin{array}{c}0.048^{*} \\
(0.026)\end{array}$ & $\begin{array}{c}0.040 \\
(0.027)\end{array}$ & \\
\hline Perceived Score & & $\begin{array}{c}0.065^{* * *} \\
(0.010)\end{array}$ & & & $\begin{array}{c}0.020 \\
(0.016)\end{array}$ & \\
\hline Precision & & $\begin{array}{c}0.108^{* * *} \\
(0.030)\end{array}$ & & & $\begin{array}{l}0.104^{*} \\
(0.057)\end{array}$ & \\
\hline Overestimation & & & $\begin{array}{c}0.080^{* * *} \\
(0.009)\end{array}$ & & & $\begin{array}{c}0.025 \\
(0.016)\end{array}$ \\
\hline Age & $\begin{array}{c}0.006^{* * *} \\
(0.001)\end{array}$ & $\begin{array}{c}0.005^{* * *} \\
(0.001)\end{array}$ & $\begin{array}{c}0.005^{* * *} \\
(0.001)\end{array}$ & $\begin{array}{c}0.008^{* * *} \\
(0.002)\end{array}$ & $\begin{array}{c}0.007^{* * *} \\
(0.002)\end{array}$ & $\begin{array}{c}0.007 * * * \\
(0.002)\end{array}$ \\
\hline Female & $\begin{array}{c}-0.059 * * * \\
(0.015)\end{array}$ & $\begin{array}{c}-0.027^{*} \\
(0.015)\end{array}$ & $\begin{array}{c}-0.027^{*} \\
(0.015)\end{array}$ & $\begin{array}{c}-0.068^{* *} \\
(0.033)\end{array}$ & $\begin{array}{c}-0.057^{*} \\
(0.034)\end{array}$ & $\begin{array}{l}-0.055 \\
(0.034)\end{array}$ \\
\hline $\ln ($ Income $)$ & $\begin{array}{c}0.035^{* * *} \\
(0.006)\end{array}$ & $\begin{array}{c}0.033^{* * *} \\
(0.006)\end{array}$ & $\begin{array}{c}0.034^{* * *} \\
(0.006)\end{array}$ & $\begin{array}{c}0.058 * * * \\
(0.016)\end{array}$ & $\begin{array}{c}0.059^{* * *} \\
(0.016)\end{array}$ & $\begin{array}{c}0.060 * * * \\
(0.016)\end{array}$ \\
\hline Finance Career & $\begin{array}{c}0.077^{* * *} * \\
(0.020)\end{array}$ & $\begin{array}{c}0.062^{* * *} \\
(0.020)\end{array}$ & $\begin{array}{c}0.063^{* * *} \\
(0.020)\end{array}$ & $\begin{array}{c}0.054 \\
(0.056)\end{array}$ & $\begin{array}{c}0.049 \\
(0.057)\end{array}$ & $\begin{array}{c}0.052 \\
(0.057)\end{array}$ \\
\hline Degree & $\begin{array}{c}0.086 * * * \\
(0.016)\end{array}$ & $\begin{array}{c}0.081^{* * *} \\
(0.016)\end{array}$ & $\begin{array}{c}0.078 * * * \\
(0.016)\end{array}$ & $\begin{array}{c}0.122^{* * *} \\
(0.034)\end{array}$ & $\begin{array}{c}0.124^{* * *} \\
(0.034)\end{array}$ & $\begin{array}{c}0.122^{* * *} \\
(0.034)\end{array}$ \\
\hline Entrepreneur & $\begin{array}{l}-0.025 \\
(0.019)\end{array}$ & $\begin{array}{c}-0.037^{*} \\
(0.019)\end{array}$ & $\begin{array}{c}-0.036^{*} \\
(0.019)\end{array}$ & $\begin{array}{l}-0.018 \\
(0.047)\end{array}$ & $\begin{array}{l}-0.019 \\
(0.047)\end{array}$ & $\begin{array}{l}-0.020 \\
(0.047)\end{array}$ \\
\hline Observations & 4,896 & 4,896 & 4,896 & 1,027 & 1,027 & 1,027 \\
\hline Literacy dummies & No & No & Yes & No & No & Yes \\
\hline Pseudo $\mathrm{R}^{2}$ & 0.0647 & 0.0809 & 0.0799 & 0.0427 & 0.0469 & 0.0450 \\
\hline
\end{tabular}

Robust standard errors in parentheses

$* * * \mathrm{p}<0.01, * * \mathrm{p}<0.05,{ }^{*} \mathrm{p}<0.1$ 
Table 9: Who Makes Household Investment Decisions?

This table reports Probit analysis of a dummy variable for whether the respondent has primary responsibility for financial investment decision-making in their household. The question asks "Which of the following best describes your role in making financial investment decisions?" Answers are "I am the primary ...", "I share responsibility", and "Someone else in the family makes financial investment decisions." Independent variables are defined in Table 2. Point estimates are reported as marginal probabilities. Columns (1) through (3) report results from the whole sample; Columns (4) through (6) from the low-financial literacy subsample, excluding those with scores higher than 3.
(1)
(2)
(3)
(4)
(5)
(6)

VARIABLES

\begin{tabular}{|c|c|c|c|c|c|c|}
\hline Actual Score & $\begin{array}{c}0.043^{* * *} \\
(0.011)\end{array}$ & $\begin{array}{c}0.013 \\
(0.012)\end{array}$ & & $\begin{array}{c}0.057^{*} \\
(0.032)\end{array}$ & $\begin{array}{c}0.035 \\
(0.034)\end{array}$ & \\
\hline Perceived Score & & $\begin{array}{c}0.050^{* * *} \\
(0.013)\end{array}$ & & & $\begin{array}{c}0.044^{* *} \\
(0.020)\end{array}$ & \\
\hline Precision & & $\begin{array}{c}0.049 \\
(0.040)\end{array}$ & & & $\begin{array}{l}-0.000 \\
(0.072)\end{array}$ & \\
\hline Overestimation & & & $\begin{array}{c}0.057^{* * *} \\
(0.012)\end{array}$ & & & $\begin{array}{c}0.044^{* *} \\
(0.020)\end{array}$ \\
\hline Age & $\begin{array}{c}-0.003^{* * *} \\
(0.001)\end{array}$ & $\begin{array}{c}-0.003^{* * *} \\
(0.001)\end{array}$ & $\begin{array}{c}-0.003^{* * *} \\
(0.001)\end{array}$ & $\begin{array}{c}0.001 \\
(0.002)\end{array}$ & $\begin{array}{c}0.000 \\
(0.002)\end{array}$ & $\begin{array}{c}0.000 \\
(0.002)\end{array}$ \\
\hline Female & $\begin{array}{c}-0.126^{* * *} \\
(0.020)\end{array}$ & $\begin{array}{c}-0.105^{* * *} \\
(0.021)\end{array}$ & $\begin{array}{c}-0.105^{* * *} \\
(0.021)\end{array}$ & $\begin{array}{c}-0.001 \\
(0.041)\end{array}$ & $\begin{array}{c}0.022 \\
(0.043)\end{array}$ & $\begin{array}{c}0.021 \\
(0.043)\end{array}$ \\
\hline $\ln ($ Income $)$ & $\begin{array}{c}-0.030^{* * *} \\
(0.009)\end{array}$ & $\begin{array}{c}-0.032^{* * *} \\
(0.009)\end{array}$ & $\begin{array}{c}-0.032^{* * *} \\
(0.009)\end{array}$ & $\begin{array}{c}-0.073^{* * *} \\
(0.020)\end{array}$ & $\begin{array}{c}-0.072^{* * *} \\
(0.021)\end{array}$ & $\begin{array}{c}-0.073^{* * *} \\
(0.021)\end{array}$ \\
\hline Finance Career & $\begin{array}{c}0.097^{* * *} \\
(0.027)\end{array}$ & $\begin{array}{c}0.090^{* * *} \\
(0.028)\end{array}$ & $\begin{array}{c}0.093^{* * *} \\
(0.028)\end{array}$ & $\begin{array}{c}0.143^{* *} \\
(0.069)\end{array}$ & $\begin{array}{c}0.139 * * \\
(0.069)\end{array}$ & $\begin{array}{c}0.146^{* *} \\
(0.070)\end{array}$ \\
\hline Degree & $\begin{array}{l}-0.005 \\
(0.021)\end{array}$ & $\begin{array}{l}-0.011 \\
(0.021)\end{array}$ & $\begin{array}{l}-0.011 \\
(0.021)\end{array}$ & $\begin{array}{l}-0.002 \\
(0.042)\end{array}$ & $\begin{array}{l}-0.007 \\
(0.043)\end{array}$ & $\begin{array}{l}-0.007 \\
(0.042)\end{array}$ \\
\hline Entrepreneur & $\begin{array}{l}-0.017 \\
(0.026)\end{array}$ & $\begin{array}{l}-0.024 \\
(0.026)\end{array}$ & $\begin{array}{l}-0.024 \\
(0.026)\end{array}$ & $\begin{array}{l}-0.056 \\
(0.058)\end{array}$ & $\begin{array}{l}-0.060 \\
(0.058)\end{array}$ & $\begin{array}{l}-0.062 \\
(0.058)\end{array}$ \\
\hline Observations & 2,882 & 2,882 & 2,882 & 650 & 650 & 650 \\
\hline Literacy dummies & No & No & Yes & No & No & Yes \\
\hline Pseudo $\mathrm{R}^{2}$ & 0.0244 & 0.0312 & 0.0310 & 0.0215 & 0.0270 & 0.0280 \\
\hline
\end{tabular}

Robust standard errors in parentheses

*** $\mathrm{p}<0.01,{ }^{* *} \mathrm{p}<0.05,{ }^{*} \mathrm{p}<0.1$ 


\section{Table 10: Overestimation, Financial Knowledge, and Advice}

This table presents Probit regressions of answers associated with the question "When considering mutual funds, it is more important to pay attention to past performance than to consider the management fees." Column (1) models the probability that the respondent answered "Don't know", and Column (2) models the propensity to respond with the wrong answer. In Column (3), the dependent variable takes the value one if the respondent answered favorably to the question, "How satisfied or dissatisfied would you be if financial planning advice or information (e.g., articles, videos, infographics) occasionally appeared in your LinkedIn news stream?"; zero otherwise. Column (4) repeats the previous regression, but in which we exclude individuals earning more than $\$ 100,000$ per year. Demographic controls include those in Tables 7 through 9, and includes dummy variables for Actual score. Point estimates are reported as marginal probabilities.

VARIABLES
Don't know Wrong ans
(1) (2) (3)

o Advice

(All)
$0.0216^{* * *}$
(0.007)

(0.012)

(0.009)

Overestimation

Observations

Demographic controls

Literacy dummies

Pseudo $\mathrm{R}^{2}$

$\begin{array}{cc}2,882 & 2,882 \\ \text { Yes } & \text { Yes } \\ \text { Yes } & \text { Yes } \\ 0.165 & 0.0201\end{array}$

4,896

Yes

Yes

0.0191
(4)

No Advice (Income $<\$ 100 \mathrm{~K})$

Robust standard errors in parentheses $* * * \mathrm{p}<0.01,{ }^{* *} \mathrm{p}<0.05,{ }^{*} \mathrm{p}<0.1$ 


\section{Figure 1: Questionnaire}

This picture dispalys an actual screenshot of the question where probabilities are solicited from respondents with respect to how they think they scored. The disctrbuions of beliefs are used to construct measures of Overestimation and Precision.

\section{Linked in。}

For the previous five multiple choice questions, you could have answered between zero and five correctly. We would like to know how many you think you got correct. Please assign a probability for each possible outcome below.

Enter whole numbers and total should add to 100

\begin{tabular}{|c|c|c|}
\hline & \multicolumn{2}{|c|}{ Total } \\
\hline Probability that I have all five correct & 0 & $\%$ \\
\hline Probability that I have exactly four correct & 0 & $\%$ \\
\hline Probability that I have exactly three correct & 0 & ]\% \\
\hline Probability that I have exactly two correct & 0 & $\%$ \\
\hline Probability that I have exactly one correct & 0 & $\%$ \\
\hline Probability that I have no correct answers & 0 & $\%$ \\
\hline Don't know & \multicolumn{2}{|c|}{$\square$} \\
\hline Prefer not to answer & \multicolumn{2}{|c|}{$\square$} \\
\hline & \multicolumn{2}{|c|}{ Total: $0 \%$} \\
\hline
\end{tabular}


Figure 2: Actual vs. Perceived Scores

This figure shows the proportion of respondents being certain of their score ("Proportion sure") by putting all probability mass at one outcome, separately for those being correct and incorrect with respect to the actual outcome (bars, right scale). The solid line traces out the average estimated correct score, labelled "Perceived score" (left scale). The dotted 45-degree line indicates a perfect match between Actual and Perceived score.

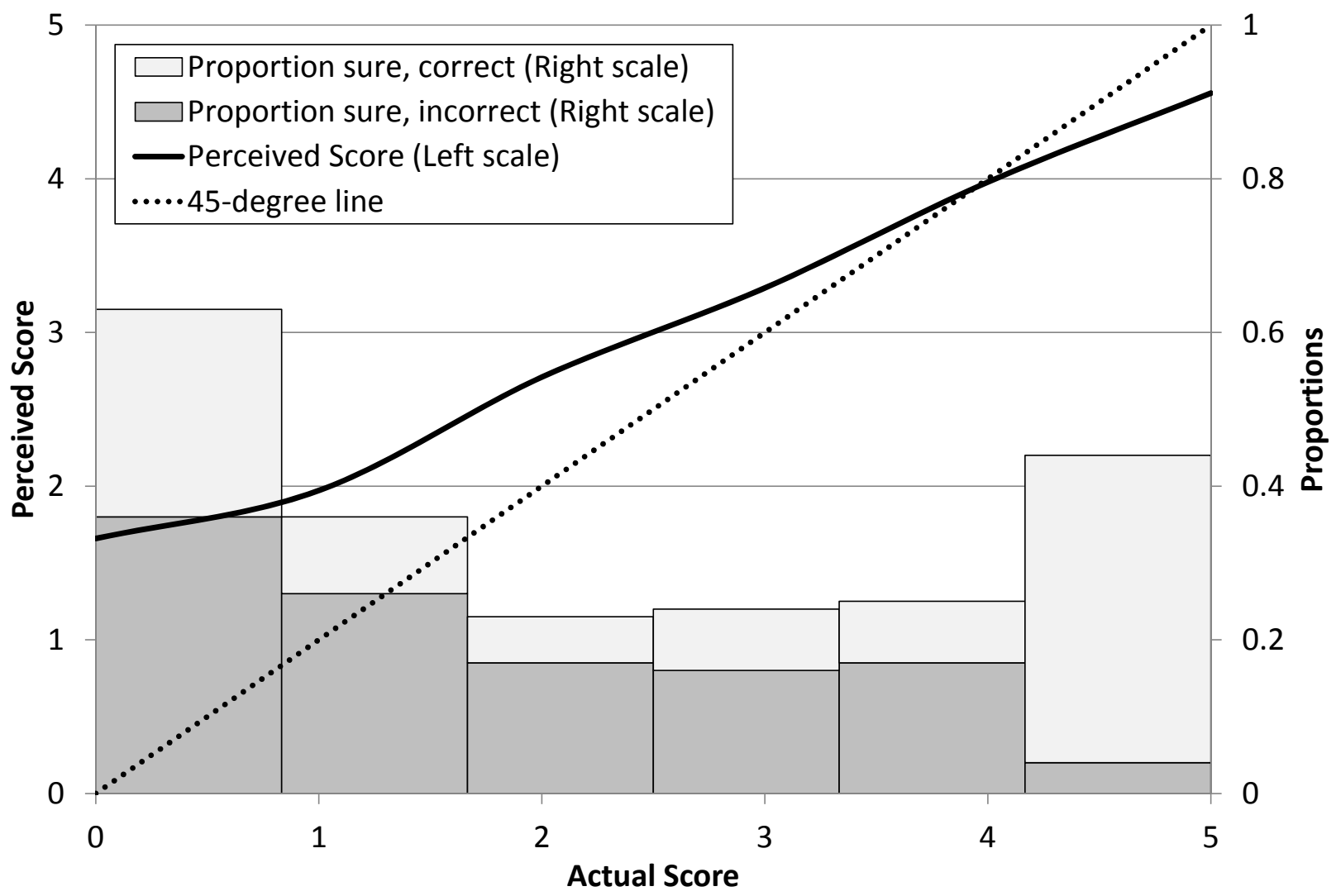


Figure 3: Distribution of Beliefs Across Scores

This graph plots average reported probabilities, sorted on actual score. The distrbuions of beliefs are used to construct measures of Overestimation (using the average) and Precision (using the dispersion).

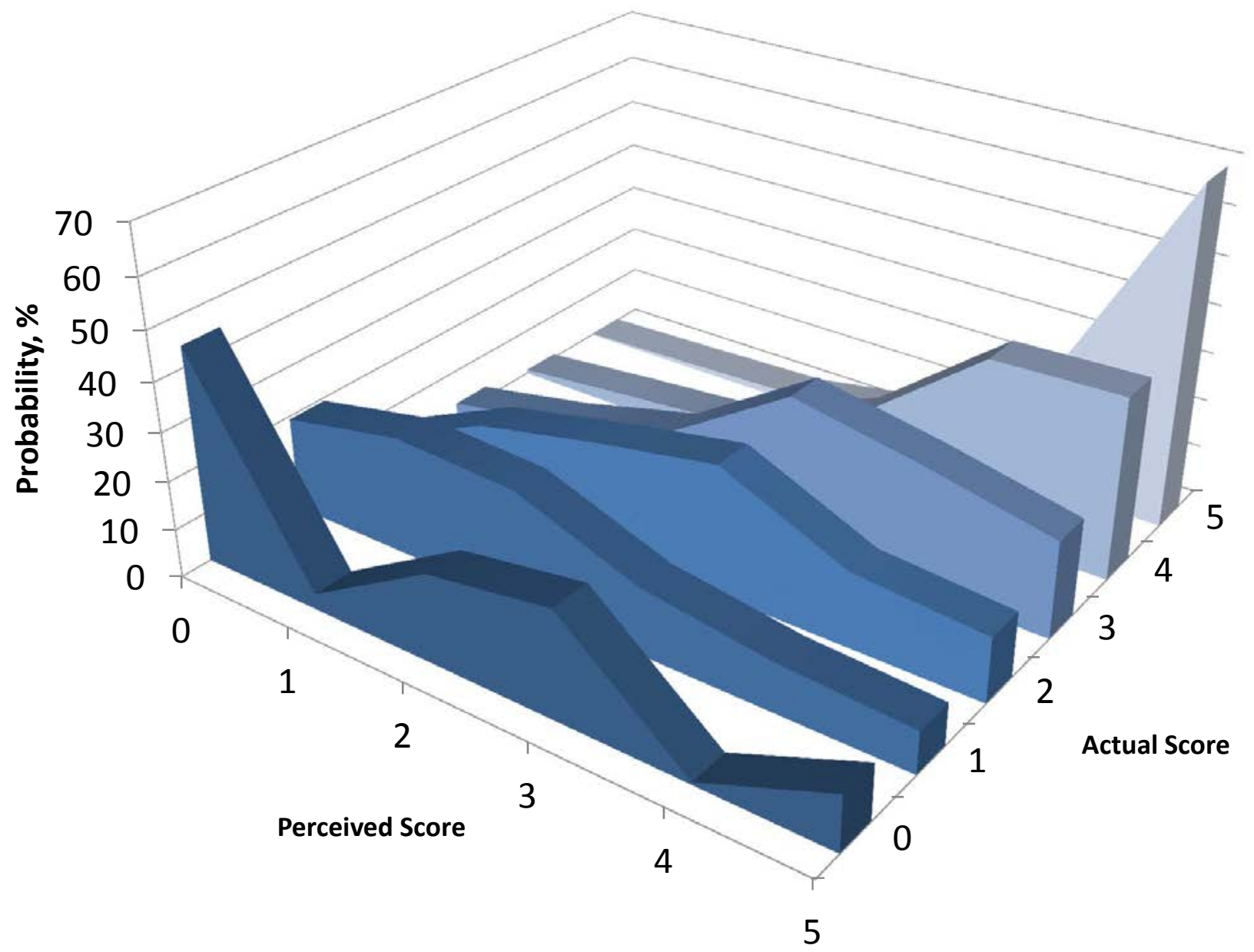




\section{Appendix A. Internet Appendix: FOR ONLINE PUBLICATION}

Appendix A.1. Responses To The Big 5 Financial Questions

- Compounding: Suppose you had $\$ 100$ in a savings account and the interest rate was $2 \%$ per year. After 5 years, how much do you think you would have in the account if you left the money to grow? Please select one.

\begin{tabular}{lrrrr} 
Answers & Wave 1 & Wave 2 & Total & Freq \\
\hline More than $\$ 102$ & 1,892 & 2,689 & 4,581 & $94 \%$ \\
Exactly $\$ 102$ & 39 & 57 & 96 & $2 \%$ \\
Less than $\$ 102$ & 51 & 85 & 136 & $3 \%$ \\
Don't know & 30 & 44 & 74 & $1 \%$ \\
Prefer not to say & 2 & 7 & 9 & $0 \%$
\end{tabular}

- Inflation: Imagine that the interest rate on your savings account was $1 \%$ per year and inflation was $2 \%$ per year. After 1 year, how much would you be able to buy with the money in this account? Please select one.

\begin{tabular}{lrrrr} 
Answers & Wave 1 & Wave 2 & Total & Freq \\
\hline More than today & 66 & 87 & 153 & $3 \%$ \\
Exactly the same & 60 & 100 & 160 & $3 \%$ \\
Less than today & 1,823 & 2,578 & 4,401 & $90 \%$ \\
Don't know & 58 & 112 & 170 & $4 \%$ \\
Prefer not to say & 7 & 5 & 12 & $0 \%$
\end{tabular}

- Diversification: Buying a single companys stock usually provides a safer return than a stock mutual fund. Please select one.

\begin{tabular}{lrrrr} 
Answers & Wave 1 & Wave 2 & Total & Freq \\
\hline True & 33 & 56 & 89 & $2 \%$ \\
False & 1,770 & 2,417 & 4,187 & $86 \%$ \\
Don't know & 197 & 391 & 588 & $12 \%$ \\
Prefer not to say & 14 & 18 & 32 & $0 \%$
\end{tabular}

- Mortgage: A 15-year mortgage typically requires higher monthly payments than a 30-year mortgage, but the total interest paid over the life of the loan will be less. Please select one.

\begin{tabular}{lrrrr} 
Answers & Wave 1 & Wave 2 & Total & Freq \\
\hline True & 1,909 & 2,702 & 4,611 & $94 \%$ \\
False & 68 & 127 & 195 & $4 \%$ \\
Don't Know & 34 & 50 & 84 & $2 \%$ \\
Prefer not to say & 3 & 3 & 6 & $0 \%$
\end{tabular}

- Bond Prices: If interest rates fall, what should happen to bond prices? 


\begin{tabular}{lrrrr} 
Answers & Wave 1 & Wave 2 & Total & Freq \\
\hline They will rise & 944 & 1,283 & 2,227 & $45 \%$ \\
They will fall & 446 & 603 & 1,049 & $21 \%$ \\
They will stay the same & 69 & 112 & 181 & $4 \%$ \\
There is no relationship between ... & 130 & 208 & 338 & $7 \%$ \\
Don't know & 411 & 658 & 1,069 & $22 \%$ \\
Prefer not to say & 14 & 18 & 32 & $1 \%$
\end{tabular}

Appendix A.2. Comparison with the NFCS

Table A.11: Data Comparison

This table presents the fraction of correct answers to each of the five literacy questions in the survey among individuals aged 25 to 64 years old along with the results from the 2012 State-by-State National Financial Capability Study (NFCS) conducted via Internet on a random sample of individuals between 25 to 64 years old in the U.S. The 2010 U.S. Health and Retirement Study (HRS) is conducted on respondents over 50 years old, and the 2009 SAVE+ study across a random sample in Germany. The fraction of respondents who had all correct answers to the first three and all five questions is reported separately, where applicable. Sample description denote from which pool subjects were drawn.

This study NFCS HRS SAVE+

\begin{tabular}{|c|c|c|c|c|c|c|}
\hline Question & Wave I & Wave II & Total & 2012 & 2010 & 2009 \\
\hline 1. Compunding & $94 \%$ & $93 \%$ & $94 \%$ & $77 \%$ & $69 \%$ & $82 \%$ \\
\hline 2. Inflation & $91 \%$ & $89 \%$ & $90 \%$ & $64 \%$ & $81 \%$ & $78 \%$ \\
\hline 3. Diversification & $88 \%$ & $84 \%$ & $86 \%$ & $51 \%$ & $63 \%$ & $62 \%$ \\
\hline 4. Mortgage & $95 \%$ & $94 \%$ & $94 \%$ & $79 \%$ & $\mathrm{n} / \mathrm{a}$ & $\mathrm{n} / \mathrm{a}$ \\
\hline 5. Bond Prices & $47 \%$ & $45 \%$ & $45 \%$ & $29 \%$ & $\mathrm{n} / \mathrm{a}$ & $\mathrm{n} / \mathrm{a}$ \\
\hline
\end{tabular}

Sample description Age 25 to 64

Age +50 Age +18

All 1-3 correct

$74 \% \quad 76 \% \quad 37 \%$

$42 \%$

$53 \%$

All 1-5 correct

$40 \% \quad 36 \% \quad 38 \% \quad 16 \%$

$\mathrm{n} / \mathrm{a}$

$\mathrm{n} / \mathrm{a}$

$\begin{array}{lllllll}\text { Observations } & 2,014 & 2,882 & 4,896 & 18,637 & 1,269 & 1,059\end{array}$




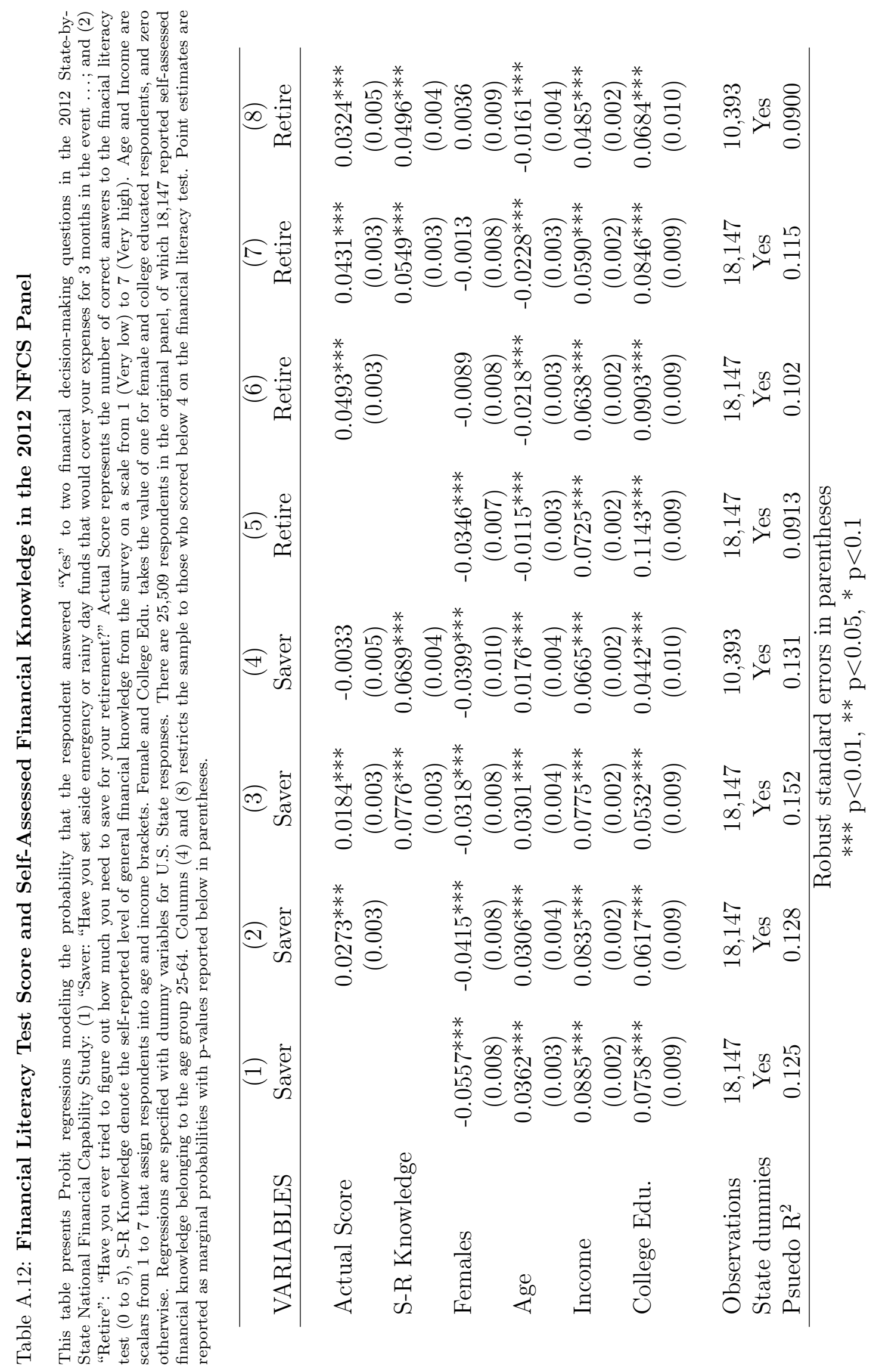

